\title{
Impactos socioculturais: os efeitos da Usina Hidrelétrica Cachoeira do Emboque em sua comunidade atingida
}

Narayana de Deus Nogueira Bregagnoli ${ }^{1}$

Franklin Daniel Rothman²

\section{Resumo}

O presente estudo analisa as perdas materiais e simbólicas que a construção da UHE Cachoeira do Emboque, MG, ocasionou à comunidade atingida pelo empreendimento. Os objetivos da pesquisa foram analisar a trajetória de deslocamento e reassentamento de algumas famílias; as condições socioculturais dessas famílias antes da construção da barragem e as condições atuais; os efeitos negativos das perdas materiais e simbólicas sofridas pelos atingidos. Utilizou-se a pesquisa de campo para a coleta de dados, com entrevistas semiestruturadas e história oral de vida. Pôde ser constatado, através da coleta e análise dos dados, que as perdas tanto materiais quanto simbólicas foram suficientes para deixar a comunidade em condições socioeconômicas precárias, uma vez que aquelas pessoas perderam meios e modos de vida, relações de vizinhança, laços familiares e o lugar vivido e construído socialmente.

Palavras-chave: Atingidos. Barragens. Impactos. Território. Perdas.

\section{Introdução}

O presente trabalho aborda efeitos sociais, materiais e simbólicos que a construção de hidrelétricas pode provocar em populações atingidas. A unidade de análise escolhida para este estudo foi constituída pela população atingida pela UHE Cachoeira do Emboque, situada ente os Municípios de Raul Soares e Abre Campo, na Zona da Mata Mineira (MG). Este empreendimento afetou a vida de noventa e quatro famílias de pequenos produtores rurais ao causar-Ihes perdas ambientais, materiais e simbólicas altamente significativas.

Das famílias atingidas, 30\% foram deslocadas para outras áreas rurais e urbanas, e as que permaneceram no local, cerca de $70 \%$, configuraram um quadro representado, em sua maioria, por pequenos proprietários, e uma menor parte por meeiros ou arrendatários. A produção agrícola atual é predominantemente voltada para a subsistência, com mão de obra familiar. Não fora possível investigar de forma aprofundada a situação socioeconômica das famílias deslocadas, uma vez que este deslocamento implicou a perda de laços com os que continuaram no local da barragem, dificultando a sua localização.

O problema da pesquisa foi delimitado a partir das leituras que abordam a temática das barragens, onde a questão das perdas sofridas pelas populações atingidas, sejam elas de natureza material ou simbólica, chamaram a nossa atenção, tanto pelos significados concretos quanto pelos abstratos ou psicológicos.

A pesquisa bibliográfica indicou que os estudos sobre os atingidos por barragens privilegiam a análise de grandes barragens que provocam deslocamentos em larga escala de pessoas e que causam impactos negativos imensuráveis. Com isso, instala-se a ideia de que pequenas barragens causam pouco ou nenhum efeito ao meio ambiente e à população. Esta argumentação tem sido usada por aqueles que defendem a construção de barragens para pequenas centrais hidrelétricas (PCHs). Essa tendência traz a necessidade de trabalhos que abordem como as populações atingidas percebem os efeitos da construção de pequenas e médias barragens. Verificou-se também que parte significativa

\footnotetext{
${ }^{1}$ Professora do IFSULDEMINAS, campus Muzambinho. Mestre em Extensão Rural pela Universidade Federal de Viçosa, UFV. narayana.nogueira@ifsuldeminas.edu.br Av. Alberto de Barros Cobra, 613, apto 302 - Centro, Pouso Alegre - MG. Telefone: (35) 3449.6164.

2Professor do departamento de Economia Rural da Universidade Federal de Viçosa - UFV. frothman@ufv.br
} 
dos estudos sobre populações atingidas tratou dos efeitos durante o período de implantação de barragens ou imediatamente posterior. Faltam trabalhos que analisem os efeitos sociais das barragens em um período mais distanciado da construção. Nesse sentido, torna-se necessário produzir trabalhos que problematizem os efeitos de longo prazo de pequenas e médias barragens nas populações atingidas.

Tendo em vista os apontamentos feitos, o presente estudo visa contribuir para preencher essas lacunas sem, contudo, encerrar todas as questões a respeito. O objeto de nosso estudo, neste trabalho, é a barragem do Emboque. Procuraremos analisar os impactos dessa construção - considerada de pequeno porte - sobre sua população atingida, passados dez anos de sua construção.

\title{
2. A expansão energética no Brasil e suas consequências
}

Segundo a Comissão Mundial de Barragens (VAINER, 2000), mais de oitocentas mil barragens já foram construídas no planeta, sendo quarenta e cinco mil de grande porte. Cerca de mil e seiscentas barragens estão em construção em todo o mundo, um negócio que movimenta US\$50 bilhões anuais. Estes empreendimentos provocam o deslocamento de cerca de quatro milhões de pessoas a cada ano, além de causar grande impacto na biodiversidade.

Nesse contexto, o Brasil é um dos vinte países onde as hidrelétricas são a principal matriz energética. Elas geram 92\% da energia consumida no país. Desde a década de 1970, duas mil barragens foram construídas no país e um milhão de pessoas já foram deslocadas. Em sua maioria, eram pequenos produtores rurais e populações indígenas.

A Eletrobrás prevê a construção de quatrocentas e noventa e quatro novas usinas hidrelétricas até 2015. Cem delas serão de pequeno porte (PCHs). A estimativa é que oitocentas mil pessoas sejam expulsas de suas terras (VAINER, 2000).

A Carta de Guaraciaba emitiu as seguintes considerações sobre as PCHs, inclusive sobre os efeitos cumulativos da implantação de várias delas em uma mesma bacia hidrográfica:

\begin{abstract}
As chamadas PCHs (Pequenas Centrais Hidrelétricas) têm causado danos enormes. Diversas empresas privadas, particularmente, vêm se aproveitando dessa modalidade de empreendimento para aumentar seus lucros, provocando prejuízos ambientais, sociais e culturais de caráter irreversível. Com efeito, as PCHs não vêm sendo alternativa às grandes barragens; ao contrário, exercem muitas vezes a função complementar, uma vez que são destinadas ao consumo durante o horário de pico. Neste caso, existe um agravante a mais, porque a mudança no regime fluvial com alterações diárias de vazão influencia em longos trechos do rio a jusante da barragem. Isto afeta diretamente a população ribeirinha, além de provocar impactos significativos nas áreas de várzeas que são ecologicamente sensíveis. Outra questão importante são os efeitos cumulativos da implantação de várias PCHs numa mesma bacia hidrográfica. Por exemplo, na região de Ponte Nova, em Minas Gerais (Alto Rio Doce), a concentração das chamadas PCHs afeta diretamente a vida de mais de 2000 famílias. Com a construção dessas barragens, toda a bacia será completamente alterada, causando enormes impactos sociais e ecológicos. (MOVIMENTO DOS ATINGIDOS POR BARRAGEM, 2002).
\end{abstract}

A política nacional de geração de energia elétrica começou a tomar forma na década de 1960, no período do regime militar, no âmbito da Eletrobrás e de suas subsidiárias - empresas estatais vinculadas ao Ministério das Minas e Energia. Esta política, que se consolidou nos anos de 1970, gerou "não apenas hidreletricidade, mas também efeitos sociais perversos" (SIGAUD, 1994, p. 1).

Definidas a partir de critérios técnicos, e sob a "pressão" de grandes grupos empresariais privados, interessados em viabilizar a realização de hidrelétricas, principalmente de grande porte, de agências financeiras internacionais com abundantes linhas de financiamento, como o Banco Mundial, estas políticas não têm considerado as implicações sociais da inundação, muitas vezes, de grandes áreas, e as obras de infraestrutura necessárias à realização desse tipo de empreendimento (SIGAUD, 1994, p. 3).

Como afirmou Sigaud,

Ao contrário do que se poderia pensar, na construção de uma hidrelétrica não estão em jogo apenas os altos interesses nacionais de produção de energia para o desenvolvimento, mas 
também os interesses particulares de grupos de empresas que se beneficiam enormemente com os investimentos do setor elétrico, assim como os interesses do capital financeiro internacional, que fornece uma parcela importante dos recursos (SIGAUD, 1994, p. 2).

As ações "sociais" geralmente são realizadas depois que o problema se instaura, e se destinam a "minimizar", "mitigar", "neutralizar" os impactos. Elas não atendem às demandas prévias da população atingida, mesmo porque esta população não é ouvida. Somente após definida a realização do empreendimento, assinados os vultosos contratos, é que se vai realizar a "avaliação de impactos sociais" (SIGAUD, 1994, p. 3).

Como as questões sociais são colocadas em segundo plano na tomada de decisões, elas passam a ser um "problema" e as soluções propostas não favorecem a população. Sigaud deixa claro o papel das empresas do setor elétrico:

[...] se pode afirmar com segurança que as empresas do setor elétrico têm sido responsáveis pelo deslocamento compulsório e atabalhoado de milhares de cidadãos brasileiros, pela sua diáspora, pelo seu empobrecimento e pela profunda desorganização de suas condições de vida (SIGAUD, 1994, p. 5).

Os defensores dos empreendimentos hidrelétricos alegam que eles contribuem para o desenvolvimento nacional e local, enquanto que os críticos destacam seus efeitos negativos. Martins (1993), ao tratar do impacto de grandes projetos, ressalta que:

Não se trata de introduzir nada na vida de ninguém. Aqui se trata de projetos econômicos de envergadura, como hidrelétricas, rodovias, planos de colonização, de grande impacto social e ambiental, mas que não têm por destinatárias as populações locais. Seu pressuposto é o da remoção dessas populações (...) (MARTINS, 1993, p. 61-63).

Santos (2002) também contesta o discurso daqueles que veem somente a dimensão econômica destes empreendimentos:

Quando nos dizem que as hidrelétricas vêm trazer, para um país ou para uma região, a esperança de salvação da economia, da integração no mundo, a segurança do progresso, tudo isso são símbolos que nos permitem aceitar a racionalidade do objeto que, na realidade, ao contrário, pode exatamente vir destroçar a nossa relação com a natureza e impor relações desiguais (SANTOS, 2002, p. 173).

Sendo assim, as hidrelétricas são exemplos do processo de modernização capitalista a que está sendo submetida a humanidade, que se caracteriza, como afirmou Ludwig (2005, p. 3), por se impor sobre a "valorização da natureza e da vida, subjugando os potenciais ecológicos, destruindo formas de organização social, desterritorializando identidades, enterrando saberes práticos e desarraigando a cultura de seus referentes locais." (grifo dos autores).

O próprio Banco Mundial, que foi um dos maiores financiadores de hidrelétricas desde a década de 1970 e, portanto, corresponsável pelo deslocamento de milhares de famílias em todo o mundo, reconhece que os projetos de construção de barragens quase sempre iniciam um processo de empobrecimento, muitas vezes representado pela perda da terra, do trabalho, da habitação, pela marginalização das famílias atingidas, pelo aumento da mortalidade, pelas dificuldades de acesso à alimentação e pela desarticulação dos atingidos (CERNEA; MCDOWELL, 2000).

Cernea et. al.. (2000, p. 23) afirma que "a expropriação da terra retira o principal fundamento sobre o qual são construídos o sistema produtivo das pessoas, suas atividades comerciais e seu meio de vida. Esta é a principal forma de descapitalização e empobrecimento de pessoas deslocadas".

lokói (1996, p. 70 apud CARVALHO, 2005) compara a situação dos atingidos por barragens com a dos sem-terra, ao considerar a falta de indenização ou os valores irrisórios pagos pelas desapropriações. De acordo com o autor, "os atingidos por barragens expulsos da terra tornaram-se sem-terra dada a irresponsabilidade dos governos no pagamento de indenizações."

A Comissão Mundial de Barragens aponta que, além de serem deslocados pela perda de suas terras, as compensações financeiras pagas aos atingidos não são suficientes para que possam restabelecer seus meios de vida em outro lugar. Os reassentamentos, quando existem, muitas vezes possuem terras de baixa qualidade ou improdutivas: 
As áreas de reassentamentos são sempre selecionadas sem uma referência ou estudos sobre a viabilidade econômica das mesmas, bem como uma consulta sobre as preferências das pessoas deslocadas. Estes são geralmente forçados a reassentar em locais com áreas ambientais degradadas no entorno da represa. Assim, as terras perdem rapidamente suas capacidades produtivas para dar suporte às populações reassentadas. (W.C.D., 2000, p. 107)

Carvalho (2005, p. 7) observa que no processo de implantação de hidrelétricas não ocorre somente o fluxo migratório "para fora" da região atingida. O autor relata que, para construção da hidrelétrica, é muitas vezes necessária a contratação de trabalhadores "de fora" da região. Nesse sentido, a obra atrai trabalhadores temporários que acarretam sérios problemas à população da região, como transformações no comércio local, no preço dos aluguéis, aumento dos índices de alcoolismo, criminalidade, prostituição e doenças sexualmente transmissíveis:

Verifica-se uma expansão, no período da obra, e, depois, um retraimento destas atividades quando do término da obra. Entretanto, fato bastante negativo, a criminalidade (principalmente a ligada ao tráfico de drogas) e a prostituição, mesmo depois de terminada a obra, raramente se desterritorializam. (CARVALHO, 2005, p. 7).

McCully (2004) reforça este ponto de vista ao afirmar que o risco de se contrair enfermidades já se inicia com a chegada dos trabalhadores da construção da barragem, que podem ocasionalmente ser portadores de enfermidades contagiosas, como sarampo, gripe, tuberculose, sífilis, AIDS, etc., o que leva à contaminação de algumas pessoas da comunidade local. Exemplo disso, o autor ainda cita dados de um documento da Organização Mundial de Saúde:

Los trabajadores que llegaban junto con sus familias hicieron que la población de los pueblos cercanos aumentadas entre 3 y 7 veces. Generalmente se asentaban en barrios humildes superpoblados, donde non tenían atención sanitaria y de la salud adecuados, y además estaban expuestos a enfermedades infecciosas, particularmente infecciones respiratorias y diarreicas, a la desnutrición y al poli-parasitismo, lo que fue perjudicial para el desarrollo de los niños. Las condiciones de vida también llevaron a la prostitución y a la promiscuidad, consecuentemente, las enfermedades de transmisión sexual eran muy comunes. (MCCULLY, 2005, p. 102)

Estudos etnográficos (SCHERER-WARREN et. al., 1990) também destacam as consequências negativas de empreendimentos hidrelétricos sobre os atingidos. Eles perdem o investimento feito por uma ou várias gerações na propriedade, a tranquilidade do espaço vivido e construído socialmente, o sentido de "lugar", seus valores e a identidade individual ou social. Além disso, observam-se perdas sociais e simbólicas, ou seja, a ruptura das relações de vizinhança, de parentesco, de comunidade, assim como as perdas de bens culturais, tais como igreja, cemitério, escola, costumes e tradições.

Rothman e Oliver (2002) enfatizam que, entre os impactos socioculturais do deslocamento compulsório, está a perda de identidade social decorrente da perda da propriedade rural e dos padrões de organização social. Hall (2005, p. 11) entende a perda de identidade como a perda da "interação entre o eu e a sociedade", sendo que a desterritorialização provocada pelo deslocamento compulsório e pela perda da propriedade é interpretada por Correa (apud SANTOS, 2002, p. 252) como a "perda do território apropriado e vivido".

Por meio dessas reflexões, pode-se perceber o quanto a perda de um território (desterritorialização) provocada pelo deslocamento compulsório é relevante para o estudo das populações atingidas por barragens, que são sempre deslocadas e realocadas em espaços "estranhos" aos seus de origem, tendo que se adaptar ao novo local, deixando para trás memórias e bens tanto materiais como simbólicos, que nunca mais serão recuperados ou refeitos no novo lugar.

Foi nos marcos dessa problemática que se inseriu esta pesquisa, que buscou analisar as perdas ou os efeitos negativos sobre a realidade sociocultural das populações atingidas pela hidrelétrica do Emboque, dez anos após sua implantação. Para alcançar esses objetivos, procurou-se:

a) analisar a trajetória de deslocamento e de reassentamento de alguns atingidos, no contexto de construção da barragem;

b) analisar a realidade sociocultural dessa população quando da construção da barragem e nos dias atuais; 
c) identificar e analisar as perdas de natureza material e simbólica sofridas por esses atingidos, de acordo com suas percepções; e

d) analisar o papel de entidades mediadoras no processo recente de mobilização de parte dessa população.

\section{Métodos, técnicas e procedimentos para a coleta de da- dos}

O delineamento de uma pesquisa implica a escolha de determinada perspectiva analítica. Este estudo se preocupou com a natureza qualitativa das informações e do processo de construção de dados, e, dessa forma, aprofundou-se "no mundo dos significados das ações e relações humanas, um lado não perceptível e não captável em equações, médias e estatísticas" (MINAYO, 1997, p. 22). Assim, a investigação do sentido ou do significado das qualidades dos dados construídos transformou-se na verdadeira busca do entendimento das percepções da população estudada.

De modo geral, esta pesquisa trabalhou com a obtenção de descrições pelos pesquisadores por meio de análise documental e de entrevistas. Trata-se de um estudo de caso viabilizado pelo contato direto com a realidade ou situação pesquisada. O nosso foco, ao estudar o problema aqui elaborado, foi verificar como ele se manifestou nas atividades e nas interações da vida cotidiana dos atores envolvidos. A sistematização da realidade estudada, em suas múltiplas dimensões, teve por finalidade responder às questões que nortearam a pesquisa.

Após ler e analisar o material teórico sobre o trabalho e definir o recorte em termos de espaço - Hidrelétrica do Emboque, localizada nos municípios de Abre Campo e Raul Soares - e de tempo, período de dez anos após a construção da barragem, iniciou-se uma primeira etapa exploratória em que foram reunidos dados obtidos do Estudo de Impactos Ambientais (EIA) e do Relatório de Impactos Ambientais (RIMA) produzidos pela ESSE Engenharia, recortes de jornais, entrevistas com os atingidos e atas de suas reuniões, gravações em vídeo e fita cassete, artigos científicos etc., arquivados pelo Núcleo de Assessoria às Comunidades Atingidas por Barragens - NACAB ${ }^{3}$, Projeto de Extensão da UFV, bem como pela secretaria do MAB Alto Rio Doce, cuja sede localiza-se em Ponte Nova/MG. Essas organizações apoiaram a tentativa de mediação dos conflitos entre a população atingida e o empreendedor na época da construção da barragem.

A fase seguinte consistiu na identificação das famílias atingidas. Inicialmente, foram consultadas as listas e documentos dos cadastros dos atingidos encontrados no acervo do MAB, do CPT regionais e do RIMA. Identificadas as famílias, inclusive os nomes de cada membro, buscaram-se informações sobre o tipo de relação do atingido com a terra, se proprietário, meeiro ou arrendatário; o tipo de produção; o padrão fundiário das propriedades e informações sobre as negociações entre atingidos e empreendedores.

Cumprida esta etapa, passou-se a se dedicar à coleta de dados e informações sobre a situação atual da população atingida. Os trabalhos de campo foram realizados em três etapas. A primeira visita a campo contou com o apoio de um informante inicial, apresentado por um membro do NACAB.

Com a ajuda da família contatada inicialmente e conhecedora daquela realidade, foi possível localizar e identificar as demais famílias em campo. A amostra foi sendo construída por meio da técnica da "bola de neve", na qual cada informante indica onde se encontram os demais (KISH, 1965). Ao se constatar a repetição das informações, interrompeu-se a coleta dos dados, quando estes se tornaram satisfatórios.

Inicialmente, ao se definir a amostragem, a coleta de dados foi realizada em duas etapas: a primeira durante o mês de agosto, por um período de dez dias; e a segunda em setembro de 2006, completando mais dez dias de trabalho em campo.

\footnotetext{
${ }^{3}$ Os trabalhos de extensão da UFV com os atingidos foram realizados de 1996 a 2002 sob o nome de NACAB. Após esse período, foi fundada uma ONG para reforçar a assessoria, que recebeu o nome de NACAB. Desde então, o projeto de extensão passou a ser chamado de $P A C A B$, que realiza os trabalhos atuais de assessoria às comunidades atingidas por barragens.

${ }^{4}$ Advogado Leonardo Pereira Rezende, que assessorou a população atingida por intermédio do NACAB.
} 
Para essa coleta de dados, utilizou-se a modalidade de entrevistas semiestruturadas ${ }^{5}$ em perguntas abertas, porém direcionadas e previamente formuladas. Pretendia-se gravar estas entrevistas, mas a maioria dos informantes (89\%) não concordou. Dessa forma, a pesquisadora conduziu as entrevistas anotando as respostas à mão.

Tais entrevistas tiveram o intuito de investigar as condições socioculturais dos atingidos, as relações de vizinhança e parentesco, as perdas materiais e simbólicas, e a recente mobilização da população.

Na primeira visita, o número de informantes foi identificado em campo. Foram entrevistadas trinta e duas famílias, sendo dezoito residentes nas comunidades rurais do distrito de Granada, onze no distrito de Bicuíba e mais três famílias de atingidos que venderam suas propriedades e se mudaram para outra região (dois de Caputira e um de Manhuaçu). Não foi possível investigar as famílias que se mudaram para o meio urbano, pois os laços sociais desses com a comunidade foram perdidos.

Para garantir uma variedade representativa da população de atingidos, bem como a diversidade de pontos de vista, foram entrevistados nas duas primeiras etapas: agricultores em geral (homens ou mulheres), proprietários rurais que moravam no meio rural; não-proprietários, incluindo meeiros e trabalhadores rurais, suas esposas e seus filhos.

Complementou-se o trabalho com entrevistas realizadas via internet ${ }^{6}$ ou pessoalmente, com alguns mediadores vinculados ao Projeto de Extensão da UFV (PACAB), NACAB, MAB e CPT, que trabalharam diretamente com a população na época do empreendimento ${ }^{7}$.

Para complementar as entrevistas realizadas nas visitas a campo anteriores, utilizou-se nessa etapa a modalidade de análise da história de vida ${ }^{8}$, onde se procurou fazer o aprofundamento da história oral ${ }^{9}$ de quatro dos atingidos entrevistados anteriormente ${ }^{10}$. Thompson $(1992$, p. 25) destaca a importância de se valer do uso da história oral em pesquisas: "A história oral oferece, quanto a sua natureza, uma fonte bastante semelhante à autobiografia publicada, mas de muito maior alcance."

Procurou-se usar a técnica da história oral com idosos, como aconselha Thompson. Para o autor,

um projeto de história oral, mais do que Ihes propiciar novos contatos sociais e, às vezes, levar a amizades duradouras, pode prestar-Ihes um inestimável serviço. Muito frequentemente ignoradas, e fragilizadas economicamente, podem adquirir dignidade e sentido de finalidade ao rememorarem a própria vida e fornecerem informações valiosas a uma geração mais jovem. (THOMPSON, 1992, p. 33)

Niemeyer e Godoi (1998) recomendam que se faça alusão à memória coletiva da população estudada: "Entre esse passado como preexistência geral que se desdobra até o presente existem "regiões da memória", onde estão contidos todos os acontecimentos que marcaram a vida do grupo". (GODOI, 1998, p. 101)

Por intermédio das entrevistas e das histórias de vida, portanto, foi possível obter elementos substanciais sobre suas trajetórias socioculturais.

É importante destacar que além das estratégias de coletas de dados já descritas, o registro em caderno de campo perpassou todas as etapas da pesquisa.

\footnotetext{
${ }^{5} \mathrm{Cf}$. Queiroz (1991): procedimentos e técnicas para o uso de gravador em pesquisas.

${ }^{6}$ Alguns informantes, tendo em vista compromissos assumidos, preferiram que as entrevistas fossem conduzidas via correio eletrônico. Primeiramente, foram enviadas as perguntas mais relevantes e, posteriormente, os contatos continuaram a ser mantidos para sanar dúvidas ou adquirir outras informações.

${ }^{7}$ Destacam-se o prof. Franklin Rothman (UFV e NACAB), Leonardo Pereira Rezende (NACAB), Ricardo Ribeiro (CPT e PUC- MG) e Padre Antônio Claret (MAB e Arquidiocese de Mariana).

${ }^{8} \mathrm{Cf}$. Haguette (1992) para mais detalhes sobre esse método, .

${ }^{9}$ De acordo com Haguette (1992), todo discurso oral que pode ser gravado, transcrito, e preservado para uso posterior é considerado história oral.

${ }^{10}$ Nesse momento, talvez por ser a terceira visita da equipe na região, através de muito diálogo e da ajuda de alguns outros informantes conhecidos pela vizinhança, a pesquisadora conseguiu, com consentimento por escrito, que esta etapa fosse gravada para que não se perdessem aspectos ricos e importantes da entrevista.
} 


\title{
4. A construção de uma usina hidrelétrica: para os atingidos, símbolo de perdas materiais
}

Todo tipo de perda, seja ela de natureza material ou simbólica, produz efeitos sociais, econômicos, culturais e psicológicos no grupo ou pessoa que sofre a ação e as consequências dela.

No caso dos atingidos por barragens, que sofrem os mais diversos tipos de perdas, as mais visíveis, e que possuem consequências mais rapidamente sentidas, são as perdas materiais.

Para os atingidos pelo Emboque que permaneceram no local, as perdas materiais são caracterizadas pela perda da totalidade, ou da quase totalidade, de suas terras, onde as partes mais férteis e agricultáveis, próximas ao leito do rio, se "perderam" para dar lugar à represa, restando somente as partes mais altas das propriedades que, por sua vez, não são próprias para a agricultura de várzea, principalmente para o cultivo de arroz, cultura que era presente em grande parte dessas propriedades. Outros cultivares também eram característicos da região como: milho, feijão, café e cana-de-açúcar, segundo nos declararam os entrevistados de nossa pesquisa. O pomar também foi caracterizado como presente em praticamente todas as propriedades, para consumo da família.

Aliada à perda da propriedade, encontramos a perda da casa, símbolo da vida pessoal e cotidiana de cada um. Desta forma, várias famílias vivenciaram essa perda, recebendo novas casas ou tendo que construí-las com recursos da indenização recebida que, na maioria dos casos, eram escassos ou insuficientes para se realizar a construção.

Dentre as famílias que permaneceram no local, algumas foram desterritorializadas: elas perderam total ou parcialmente seus meios de sobrevivência; precisaram modificar suas condições econômicas e restringiram-se à agricultura de subsistência, retirando, do pouco que sobrou de suas terras, o mínimo para sobreviver. Dessa forma, as produções rurais foram afetadas pela construção da barragem. A redução da extensão das terras e, consequentemente, das áreas cultivadas, causou impactos na economia e nos hábitos alimentares ${ }^{11}$ da comunidade. Antes da barragem, os moradores da comunidade consumiam produtos retirados da propriedade. Atualmente, precisam comprar nos supermercados da cidade próxima, quando têm condições financeiras.

Sem o meio de sustento que antes vinha das produções agrícolas, grande parte dessas pessoas conta atualmente com aposentadorias que mal garantem a sobrevivência de suas famílias. Os relatos abaixo explicitam essa situação vivenciada pela comunidade:

'A gente vivia da agricultura, plantava tudo para consumir e vender, agora não tem onde plantar. Nós tinha [sic] era brejo pra plantar arroz. Era bom por demais. Trazia nosso sustento. Agora acabou tudo.' (Informante proprietário, 48 anos)

'O brejo que a gente tinha foi atingido. Pagaram menos. Antes produzia muito arroz. Agora tem que comprar no supermercado. Era meeiro também e tive a propriedade atingida. A vida piorou porque agora tem que comprar tudo no mercado. Vendia o arroz que colhia antes, o arroz que colhemos quando veio a empresa deu pra mais 4 anos.' (Informante proprietário, 66 anos)

\begin{abstract}
'Antes eu tinha feijão, feijão e pomar para tirar as frutas para as crianças e pra gente comer em casa, mas o feijão era pra vender, vender e comer. Agora compro as coisas no mercado, tem que ir na [sic] cidade ou na [sic] venda em Granada pra comprar.' (Informante proprietário, 52 anos)
\end{abstract}

Com a diminuição do tamanho das propriedades, houve uma queda relevante nas atividades econômicas, tanto na de produtor rural, que aqui se interpreta como o proprietário, como na de trabalhador rural, que engloba meeiros, parceiros e assalariados.

Como a maior parte dos proprietários se encontra numa faixa etária acima dos quarenta e cinco anos, grande parte já se aposentou. A aposentadoria também aponta indícios de outras modificações no local:

\footnotetext{
${ }^{11} \mathrm{~A}$ questão da restrição alimentar ocasionada ao cotidiano dos atingidos nos leva a trabalhar com a noção de segurança alimentar e nutricional que significa "garantir a todos acesso a alimentos básicos de qualidade, em quantidade suficiente, de modo permanente e sem comprometer o acesso a outras necessidades essenciais, com base em práticas alimentares saudáveis. Contribuindo, assim, para uma existência digna, em um contexto de desenvolvimento integral da pessoa humana." (CHAVES, 2006).
} 
'Estamos com umas vacas pra vender um pouco de leite, mas nos aposentamos, aí ajuda na renda, agente está cansado de trabalhar também, já estamos velhos e cansados.' (Informante proprietário, 69 anos)

'Meus filhos plantam aqui porque já estamos velhos, aposentados, a gente ajuda no que pode, mas eles que tocam a lavoura.' (Informante proprietária, 71 anos)

'Ah, agora que aposentamos a gente planta o que dá aqui no terreno, e só pra comer mesmo."' (Informante proprietário, 67 anos)

Outros acabaram tendo que optar pelo trabalho assalariado temporário, uma vez que perderam a condição de meeiros e não possuem alternativa econômica. Ao serem desterritorializados, esses atingidos perderam terras e meios de sobrevivência, e acabaram excluídos da sociedade. Como abordado anteriormente por Vainer (2003), também tornam-se deslocados economicamente, uma vez que tiveram suas atividades econômicas interrompidas ou modificadas.

Outro fator relevante no conjunto dos problemas advindos da construção da hidrelétrica está relacionado à piora do acesso da comunidade à cidade de Raul Soares, ponto de referência para essa população na procura de serviços como assistência médica, escolas, supermercados, etc. Com a construção da represa, a distância da estrada de chão aumentou em média em 15 km, o que dificulta a ida à cidade, uma vez que grande parte da comunidade ainda usa a charrete como meio de transporte, pois são poucas as famílias que possuem carro ou moto para se deslocarem.

\section{As perdas simbólicas}

As questões sobre as perdas do território vão além das perdas físicas e materiais de dado espaço geográfico, onde os atingidos, muitas vezes, não possuem direitos legais de posse sobre determinada propriedade, como abordado em Scherer-Warren et al. (1988 e 1990).

Além das perdas materiais, surgem as perdas simbólicas, tais como: culturais, relações de vizinhança e afetivas, manifestações religiosas, sociabilidade, etc., também abordadas no referencial conceitual do presente trabalho.

As palavras a seguir mostram como a população percebe essas questões:

‘Nasci e fui criada aqui. Tinha dia que chorava só de pensar que iriam alagar as árvores do local. [Ela se emociona e chora ao iniciar a conversa] Não gosto de falar nisso, é muito triste. 0 marido não gosta e nem deixa eu [sic] falar nisso. Você lembra da estrada desde que nasce; ia pra escola a pé... E ver a estrada sumir e tudo sumir...' (Informante meeira, 65 anos)

‘Na questão das barragens o que mais machuca é o psicológico. Perdemos as cachoeiras, o futebol e a família, tudo isso deixou saudade.' (informante proprietário, 60 anos)

'As lembranças não se fecham e as feridas doem muito.' (informante proprietária, 45 anos)

No caso dos atingidos do Emboque, grande parte dessa população de trabalhadores rurais era composta, antes da construção da barragem, por pequenos proprietários (que haviam herdado as terras) e, em menor proporção, meeiros, numa estrutura basicamente formada pela agricultura familiar.

Pelo que se constatou durante a coleta de dados, uma parte dos proprietários vendeu suas terras, indo para outras comunidades rurais de cidades vizinhas, ou até mesmo para áreas urbanas.

Esse contingente que saiu da região, além de ter sido desterritorializado, teve de, por conseguinte, refazer todas as relações sociais no novo local em que foi inserido, isso sem contar com os laços familiares que foram cortados ou distanciados.

Outro exemplo das perdas simbólicas é o time de futebol local, que mantinha jogos semanais, como forma de unir a comunidade, de socializar. $\mathrm{O}$ alagamento do campo de futebol acabou com as partidas no local e deixou saudades entre os que vivenciaram aquela época.

Alguns espaços que eram considerados lugares carregados de simbologia afetiva e palco para os encontros sociais, lazer e divertimento da população, também foram desterritorializados para que pudessem territorializar a barragem.

Também se destaca, como exemplo de perdas simbólicas, a cachoeira que ficou submersa, e é mencionada várias vezes pelos moradores com muita emoção e saudosismo. 
Não é de se estranhar como a empreendedora possui uma representação diferente da dos atingidos no que diz respeito aos lugares de lazer e prazer, uma vez que construiu uma praça no distrito de Granada, como forma de "compensar" a falta da cachoeira, acreditando esta ser uma solução equivalente a um espaço dotado de símbolos, dentro de um ambiente natural e saudável, em contato direto com a natureza e tudo o que ela proporciona de agradável. Além da perda do lugar de encontro e afetividade, a perda da cachoeira não deixa de ser um importante impacto ambiental, causado pelo alagamento da represa:

\footnotetext{
'No verão a gente ia sempre pra cachoeira, umas sessenta pessoas; e jogar bola também. Isso acabou, ninguém quer pegar doença na água: tem verme.' (Informante proprietário, 57 anos)

'O pessoal gostava da cachoeira, da areia, das pedras. Hoje não tem nada, fizeram aquela porcaria em Granada e ninguém faz nada. O rio é diferente, a água é viva, rio parado é morto.'(Informante meeiro, 49 anos)
}

\begin{abstract}
'Ah, antes era bão [sic] por demais. Reunia todo mundo; ia domingo pescar na cachoeira, tomar banho, jogar bola... Agora não tem mais nada. Tem um campinho pequeno que o pessoal joga bola, mas a gente não pode nadar na represa: é suja e tem doença, e a água é parada, não tem graça.' (Informante proprietária, 63 anos)
\end{abstract}

Sendo assim, percebemos o quanto a questão das perdas é relativa de acordo com a ótica de quem a analisa; porém, não nos deixa dúvidas a compreensão do quanto elas são significativas e profundamente marcantes para quem as sofre diretamente.

\title{
6. Considerações finais
}

Os resultados apresentados no presente estudo de caso permitem realizar algumas inferências a respeito, de acordo com o problema de pesquisa que deu origem a esse estudo.

Apesar das dificuldades que enfrentam, esses pequenos agricultores permanecem e pretendem continuar nas pequenas parcelas de terra que lhes sobraram, na tentativa de não perder os poucos laços sociais e familiares que ali restaram, como também de permanecer no território onde possuem raízes e sentimento de pertencimento.

Para os moradores, que estão inseridos em uma construção social de traços culturais (tais como o trabalho com a terra, as relações de trabalho tipicamente familiares, a religiosidade e a sociabilidade), traços de tradições perpassam gerações e ainda permanecem no local. O lugar, para essa comunidade, visto como espaço para a vida cotidiana e para as relações sociais apresenta elementos que denotam significados compartilhados de maneira importante. Ao projetarem em seus imaginários as lembranças de um lugar melhor antes da construção da barragem, lançam deslumbramentos de como seria melhor se aquela não tivesse sido ali territorializada.

Ao se verem ameaçados pela realidade que descaracterizaria o lugar e desterritorializar pessoas e lugares importantes para a subjetividade daquela comunidade, tentaram inicialmente se articular com o intuito de permanecer no território e, se não fosse possível, garantir alguns direitos para que pudessem contemplar uma posterior sobrevivência. Porém, encontravam-se desinformados, mal articulados e unidos em um contexto em que a solidariedade e os interesses comuns não eram recíprocos.

Dessa forma, a comunidade acabou falhando em sua mobilização inicial, que ainda foi afetada, segundo os atingidos, pela cooptação de membros diretores da associação, acabando por dar fim a ela.

Analisando tais acontecimentos, pudemos perceber que a reciprocidade dessa comunidade estava comprometida, talvez por diferenças socioeconômicas, ou talvez por motivos desconhecidos, fazendo com que a percepção sobre as negociações individuais se tornasse mais interessante para uma parte dessa população, desunindo-a e fazendo com que o grupo perdesse a força coletiva. Em outras palavras, pode ter faltado uma maior identidade de objetivos, necessária ou suficiente para promover a união e a luta coletiva em prol de seus objetivos.

Porém, ao "optarem" pelas negociações individuais e pelas vantagens pessoais, enfrentando dificuldades impostas pela realidade da construção da barragem e das negociações, esses atingidos 
passaram a compreender agora a necessidade de um trabalho em conjunto.

Dessa forma, ao sofrerem e apreenderem as consequências das perdas materiais e simbólicas, parte dessa comunidade se articulou de alguns anos para cá, com o intuito de tentar recuperar ou amenizar o que foi perdido.

Ao deslindar essas especificidades do caso Emboque, acredita-se que o presente trabalho, longe de encerrar ou esgotar este assunto, possa auxiliar na compreensão e reflexão sobre os impactos negativos advindos da construção das hidrelétricas, que causam perdas materiais e simbólicas nas comunidades atingidas por barragens, mas também conscientizar populações e simpatizantes da causa sobre a necessidade de atuar de forma diretamente inversa à das empresas do setor energético, esclarecendo os atingidos com o maior número de informações possível sobre o projeto e suas consequências. Finaliza-se o estudo concordando com Tuan (1983), que reflete sobre o direito e a necessidade do ser humano de ser, estar e pertencer a um lugar, símbolo de liberdade, de humanização, de ação, de valores estabelecidos e de significados construídos de forma coletiva. Por todas essas representações, Tuan (1983, p. 61) afirma que "os seres humanos necessitam de espaço e de lugar", espaços esses que precisam ser respeitados e vistos sob outras formas pelo setor elétrico, bem como pelos órgãos ambientais e governamentais.

Essa reflexão sobre os resultados negativos de tais empreendimentos pode levar à elaboração de novas políticas públicas que possam reavaliar todo o processo de licenciamento e buscar alternativas na legislação para que as implicações dos efeitos negativos, tanto no meio ambiente como na população, sejam evitadas. Também se entende que a busca por outras fontes energéticas menos prejudiciais aos seres humanos devem ser priorizadas pelos governantes, ainda que em detrimento dos interesses mais particulares das empresas que se envolvem no complexo processo de construção de usinas hidrelétricas.

\section{Social and cultural impacts: the effects of the Cachoeira do Emboque Dam in its affected community}

\section{Abstract}

The present study analyzed the material and symbolic losses caused by the building of the Cachoeira do Emboque Dam, in MG, in the community affected by the enterprise. The objectives of this research was to analyzes the displacement and resettlement of theses affected families; their social and cultural conditions before the dam and actual; the negative effects of the material and symbolic losses suffered by this population. It was used a field research to collect the data, using semi structured interviews and oral life history. It was possible to detect that the material and symbolic losses were sufficient to let the social and cultural conditions of this community precarious, once they lost their way of life, their financial conditions, neighborhood, family ties and the lived and socially composed place.

Key words: Affected. Dams. Impacts. Territory. Losses.

\section{Referências bibliográficas}

CARVALHO, O. A. Migrações compulsórias, territorialidade e lugar na implantação de hidrelétricas na bacia hidrográfica do rio Uruguai. In: ENCONTRO CIÊNCIAS SOCIAIS E BARRAGENS, 1., 2005, Rio de Janeiro. Anais... Rio de Janeiro, 2005. 1 CD-ROM.

CERNEA, M.; MCDOWELL, C. Risks and reconstruction: experiences of resettles and refugees. Washington D. C.: The World Bank, 2000.

CHAVES, Marcelo. Fome e desnutrição infantil. [2006] Disponível em: <http://artigos.netsaber.com. br/resumo_artigo_3796/artigo_sobre_fome_e_desnutricao_infantil >. Acesso em: 14 maio 2013. 
HAGUETTE, T. M. F. Metodologias qualitativas na sociologia. Petrópolis: Vozes, 1992.

HALL, S. A identidade cultural na pós-modernidade. Rio de Janeiro: DP\&A, 2005.

SANTOS, M.; BECKER, B. K. (Orgs.) Território, territórios: ensaios sobre o ordenamento territorial. 2. ed. Rio de Janeiro: DP\&A, 2006.

IOKOI, Z. G. Igreja e camponeses. São Paulo: HUCITEC, 1996.

LUDWIG, M. P. Descortinando a paisagem: a construção social do espaço e o sentido de lugar: uma comunidade rural da Zona da Mata de Minas Gerais nos umbrais do século XXI. 2003. 239 f. Tese (Doutorado em Estruturas Ambientais Urbanas). Universidade de São Paulo, São Paulo, 2003.

MOVIMENTO DOS ATINGIDOS POR BARRAGEM. Carta de Guaraciaba. Nov. 2002. mimeo.

McCULLY, P. Ríos silenciados: ecología y política de las grandes represas. Santa Fé: Proteger, 2004.

NIEMEYER, A. M.; GODOI, E. P. (Orgs.) Além dos territórios. São Paulo: Mercado das Letras, 1998.

ROTHMAN, F.; OLIVER, T. From local to global: the anti-dam movement in Southern Brazil, 19791992. In: SMITH, J.; JOHNSTON, H. (Orgs.) Globalization and resistance: transnational dimensions of social movements. Lanham: Rowman and Littlefield, 2002, p. 115-132.

SANTOS, M. A natureza do espaço. São Paulo: Edusp, 2002.

SANTOS, M.; SOUZA, M. A. A.; SILVEIRA, M. L. (Orgs.) Território, globalização e fragmentação. São Paulo: Hucitec, 2002.

SCHERER-WARREN, I.; REIS, M. J.; BLOEMER, N. M. Alto Uruguai: migração forçada e reatualização da identidade camponesa. Travessia Revista do Migrante, ano 2, n. 6, p. 29-33, jan.-abr., 1990.

SIGAUD, L. M. Implicações políticas e sociais de grandes projetos hidrelétricos sobre as populações indígenas e camponesas. Instituto de Estudos Avançados, USP, n. 16, mar. 1994. (Coleção Documentos, Série Ciências Ambientais.)

THE REPORT OF THE WORLD COMMISSION ON DAMS, 2000. CD-ROM.

THOMPSON, Paul. A voz do passado: história oral. São Paulo: Paz e Terra, 1992.

TUAN, YI-FU. Espaço e lugar: a perspectiva da experiência. São Paulo: DIFEL, 1983.

VAINER, C. B. Águas para vida. Jornal do Brasil, Rio de Janeiro, p.9, 4 abr. 2000.

. Termoelétricas. Disponível em: <http://www2.uol.com.br/ecologia/pesquisa-public/ecologia/ ecologia_90_destaque.htm>. Acesso em: 25 mar. 2005.

\section{Histórico editorial}

Recebido: 27/03/2013

Avaliação e copidesque: 01/04/2013 a 23/10/2013 